\title{
S100A4 expression is associated with lymph node metastasis in papillary microcarcinoma of the thyroid
}

\author{
Hye Sook Min ${ }^{1}$, Gheeyoung Choe ${ }^{2,3}$, Sung-Won Kim ${ }^{4,5}$, Young Joo Park ${ }^{6,7}$, Do Joon Park ${ }^{7}$, \\ Yeo-Kyu Youn ${ }^{5}$, Seong Hoe Park ${ }^{3}$, Bo Youn Cho $^{7}$ and So Yeon Park ${ }^{2,3}$ \\ ${ }^{1}$ Department of Pathology, National Cancer Center, Goyang, Gyeonggi, Korea; ${ }^{2}$ Department of Pathology, \\ Seoul National University Bundang Hospital, Seongnam, Gyeonggi, Korea; ${ }^{3}$ Department of Pathology, Seoul \\ National University College of Medicine, Seoul, Korea; ${ }^{4}$ Department of Surgery, Seoul National University \\ Bundang Hospital, Seongnam, Gyeonggi, Korea; ${ }^{5}$ Department of Surgery, Seoul National University College of \\ Medicine, Seoul, Korea; ${ }^{6}$ Department of Internal Medicine, Seoul National University Bundang Hospital, \\ Seongnam, Gyeonggi, Korea and ${ }^{7}$ Department of Internal Medicine, Seoul National University College of \\ Medicine, Seoul, Korea
}

\begin{abstract}
The detection of papillary microcarcinomas of the thyroid is increasing due to frequent use of ultrasound and fine-needle aspiration biopsy. Although most of the papillary microcarcinomas remain quiescent and follow an indolent clinical course, some behave aggressively and metastasize early, giving rise to clinically significant disease. There have been few studies concerning factors predictive of lymph node metastasis in papillary microcarcinomas. We analyzed the expression of S100A4, cyclin D1, p27 and MUC1, the presence of the $B R A F^{V 600 E}$ mutation and the clinicopathological features of the tumors, including patient age, tumor size ( $\geq 5 \mathrm{vs}$ $<5 \mathrm{~mm}$ ), extrathyroidal extension, multifocality, histological subtype, sclerosis and encapsulation, in a series of 198 papillary microcarcinomas in relation to lymph node metastasis to determine the predictive factors of lymph node metastasis. On univariate analysis, tumor size of $5 \mathrm{~mm}$ or more, extrathyroidal extension, multifocality, sclerosis and the expression of S100A4 and cyclin D1 predicted lymph node metastasis, whereas patient age, expression of p27 and MUC1 and the BRAF ${ }^{1600 E}$ mutation did not. Moreover, tumor size $5 \mathrm{~mm}$ or more, multifocality and expression of S100A4, especially its strong expression in the invasive fronts, were significantly associated with macrometastasis and lateral node metastasis. On multivariate analysis, multifocality and expression of S100A4 were found to be common independent predictive factors of lymph node metastasis, macrometastasis and lateral node metastasis. In conclusion, S100A4 expression in papillary microcarcinomas may indicate the presence of nodal metastasis. Thus, S100A4 immunohistochemistry may be valuable for predicting metastatic potential in papillary microcarcinomas.
\end{abstract}

Modern Pathology (2008) 21, 748-755; doi:10.1038/modpathol.2008.51; published online 21 March 2008

Keywords: thyroid; papillary microcarcinoma; lymph node; metastasis; S100A4

The frequent use of thyroid ultrasonography and fine-needle aspiration biopsy and improvements in these procedures have increased the observed incidence of papillary microcarcinoma of the thyroid. This is defined, according to the World Health Organization, as papillary carcinoma measuring $1.0 \mathrm{~cm}$ or less. ${ }^{1}$ It is the most common form of papillary carcinoma, ${ }^{1}$ comprising almost half of the

Correspondence: Dr SY Park, Department of Pathology, Seoul National University Bundang Hospital, 300 Gumi-dong, Bundang-gu, Seongnam-si, Gyeonggi-do, 463-707, Korea.

E-mail: sypmd@snu.ac.kr

Received 09 November 2007; revised 16 February 2008; accepted 18 February 2008; published online 21 March 2008 papillary thyroid carcinomas reported in recent studies. $^{2-4}$

Most papillary microcarcinomas remain silent and have a slow clinical course, but some behave aggressively, with local recurrence ${ }^{5-7}$ and early distant metastasis, ${ }^{5,7}$ giving rise to clinically significant disease. Furthermore, a papillary microcarcinoma may occasionally be the primary lesion of a lymph node metastasis presenting clinically as a neck mass. However, the predictive factors for papillary microcarcinomas with the potential to behave aggressively have not been established. In large papillary thyroid carcinomas, the predictors of relapse or persistent disease are well established and include age at diagnosis ( $\geq 45$ years), histological 
subtype (tall-cell, columnar-cell and diffuse sclerosing variants), large tumor size, extrathyroidal extension and nodal metastasis. ${ }^{8}$ Although its clinical significance in papillary microcarcinomas is somewhat controversial, several authors have reported that lymph node metastasis at presentation is correlated with loco-regional recurrence in papillary microcarcinomas. ${ }^{5,9-11}$ Moreover, lymph node metastasis is reported to be associated with distant metastasis of papillary microcarcinomas..$^{9-11}$ In the new TNM (tumor, node, metastases) staging system, lymph node metastasis is a more important factor than tumor size in overall staging. ${ }^{12}$

Overexpression of cyclin D1, ${ }^{13}$ S100A $4^{14}$ and MUC1, ${ }^{15}$ loss of $\mathrm{p} 27^{13,16}$ and presence of the $B R A F$ mutation $^{17,18}$ have been suggested as important predictive factors for relapse or nodal metastasis of papillary thyroid carcinoma. However, to our knowledge, there have been few studies of the predictive factors for lymph node metastasis in papillary microcarcinomas, except for expression of cyclin D1 and p27, which were reported to be associated with lymph node metastasis. ${ }^{19-21}$

In the present study, we investigated the predictive factors of lymph node metastasis in a large series of papillary microcarcinomas by analyzing clinicopathological variables, including patient age, tumor size ( $\geq 5$ vs $<5 \mathrm{~mm}$ ), extrathyroidal extension, multifocality, histological subtype, sclerosis and encapsulation, expression of S100A4, cyclin $\mathrm{D} 1, \mathrm{p} 27$ and MUC1 and presence of the $B R A F^{\mathrm{V} 600 \mathrm{E}}$ mutation.

\section{Materials and methods}

\section{Materials}

A total of 198 patients with papillary microcarcinoma who underwent surgery at Seoul National University and Seoul National University Bundang Hospital between 2004 and 2006 were included in this study. First, we selected 150 patients with papillary microcarcinoma who underwent neck dissection (central neck dissection or combined central and lateral neck dissection) of five or more lymph nodes, in addition to total thyroidectomy, to evaluate lymph node status. Lateral neck dissection was performed when clinically apparent or suspicious lateral node metastases were detected by preoperative imaging studies. All the cases were suspected to be cancers on the basis of ultrasound and fine-needle aspiration biopsy (non-incidental papillary microcarcinoma), two of which presented with lymph node metastasis. Forty-five patients showed preoperatively detectable lymph node enlargement on ultrasound or computed tomography, and 34 of them $(76 \%)$ had metastasis. Seventy-four patients had cervical lymph node metastasis on histopathological examination, and 26 of these $35 \%$ of the patients with lymph node metastasis) had lateral node metastases. We also collected 48
Table 1 Clinicopathological characteristics of 198 papillary microcarcinomas

\begin{tabular}{lr}
\hline & No. (\%) \\
\hline Patient age (year), range (median) & $20-78(48)$ \\
Age $\geq 45$ years & $116(59)$ \\
Gender (F/M) & $170 / 28$ \\
Tumor size $\geq 5 \mathrm{~mm}$ & $152(77)$ \\
Extrathyroidal extension & $70(35)$ \\
Multifocality & $64(32)$ \\
Lymph node metastasis & $74(37)$ \\
Follicular variant & $22(11)$ \\
Sclerosis & $119(60)$ \\
Encapsulation & $39(20)$ \\
\hline
\end{tabular}

patients with papillary microcarcinoma, which was an incidental finding after thyroidectomy performed for other diseases (incidental papillary microcarcinoma). None of the cases underwent lymph node dissection and were regarded as a group without lymph node metastasis. Clinicopathological characteristics of the cases are summarized in Table 1.

\section{Histopathological Evaluation}

All specimens were fixed in $10 \%$ neutral-buffered formalin, embedded in paraffin wax and stained with hematoxylin and eosin (H\&E) for histological examination. The diagnosis of papillary microcarcinoma was based on characteristic architectural features, i.e., the presence of true papillae and/or nuclear changes such as ground glass nuclei, nuclear pseudo-inclusions and nuclear grooves. The following clinicopathological variables were recorded: gender, age ( $\geq 45$ vs $<45$ years), tumor size $(\geq 5$ vs $<5 \mathrm{~mm}$ ), extrathyroidal extension, multifocality, histological subtype (conventional pattern vs follicular pattern), sclerosis and encapsulation. Extrathyroidal extension is defined as extension beyond the thyroid capsule, including microscopic extension.

\section{Tissue Array Construction}

Tissue arrays were used for high throughput analysis. After screening the slides of each case, we selected a paraffin block that was well fixed and contained a representative tumor section. One tissue column of $4 \mathrm{~mm}$ in diameter including the tumor invading fronts was taken from the selected paraffin block and arranged in a separate new paraffin block with 24 holes, using a trephine apparatus (Superbiochips Laboratories, Seoul, Korea). Each tissue microarray slide contained 24 specimens and provided sufficient areas for histopathological examination. As an internal control, we inserted the tissue columns of normal thyroid or Hashimoto's thyroiditis in two holes of each tissue microarray block. 


\section{Immunohistochemical Analysis}

Four micrometer-thick sections from the tissue array blocks were deparaffinized, rehydrated in graded alcohols, and processed using a DAKO Envision detection kit (DakoCytomation, Carpinteria, CA, USA). Briefly, antigen retrieval was performed in a microwave oven for $15 \mathrm{~min}$ in $10 \mathrm{mM}$ citrate buffer $\mathrm{pH}$ 6.0. Endogenous peroxidase activity was blocked with a $3 \% \mathrm{H}_{2} \mathrm{O}_{2}$-methanol solution, and the slides were incubated in 10\% normal goat serum for $30 \mathrm{~min}$ to prevent nonspecific staining. They were then incubated for $1 \mathrm{~h}$ at room temperature with appropriately diluted primary antibody. The following antibodies were used: S100A4 (polyclonal; 1:1500; DakoCytomation), cyclin D1 (clone SP4; 1:100; Labvision, Fremont, CA, USA), p27 ${ }^{\text {kip1 }}$ (clone SX53G8; 1:200; DakoCytomation) and MUC1 (clone Ma552; 1:100; Novocastra, Newcastle, UK). Thereafter, the sections were incubated with DAKO Envision/HRP for $30 \mathrm{~min}$. Diaminobenzidine was used as chromogen, and the sections were counterstained with Mayer's hematoxylin. As a negative control, non-immune serum was substituted for the primary antibody.

S100A4 expression was cytoplasmic and/or nuclear. Cyclin D1 and p27 ${ }^{\text {kip } 1}$ were mostly nuclear, with occasional cytoplasmic staining, and only nuclear staining was counted. MUC1 was found in the plasma membrane and occasionally in the cytoplasm.

The expression of markers other than $\mathrm{p} 27^{\mathrm{kip} 1}$ was graded as follows: 0, no staining or staining in less than $10 \%$ of the tumor cells; $1+$, staining in $10-25 \%$ of the cells; $2+$, staining in $26-50 \%$ of the cells; $3+$, staining in $51-75 \%$ of the cells; $4+$, staining in more than $75 \%$ of the cells. For statistical analysis, cases with any degree of positive staining were grouped as positive. For S100A4, the presence or absence of accentuation of expression at invasive fronts was also recorded. For p2 $7^{\text {kip } 1}$, no staining or staining in less than $10 \%$ of the tumor cells was defined as the loss of $\mathrm{p} 27^{\mathrm{kip} 1}$.

\section{Detection of the BRAF Mutation: Polymerase Chain Reaction and Sequencing}

It proved possible to extract genomic DNA in 60 of the cases of papillary microcarcinoma for which additional tumor tissue blocks were available. Briefly, the tumor areas were marked using 4micronthick H\&E stained sections as guides. Then, the marked areas were matched with de-waxed, but unstained, $20-\mu \mathrm{m}$-thick sections. The tumor areas were dissected from the unstained slides and transferred into Eppendorf tubes. After dissection, the blocks were cut into $4-\mu \mathrm{m}$ sections for $\mathrm{H} \& \mathrm{E}$ staining to confirm tumor continuity. All samples were then digested with proteinase $\mathrm{K}$ for more than $24 \mathrm{~h}$ at $56^{\circ} \mathrm{C}$, and DNA was isolated from the digested tissue using a General Biosystems Tissue SV mini kit (General Biosystems, Seoul, Korea). We amplified BRAF exon 15 by the polymerase chain reaction (PCR) using primers: forward, 5'-GCTTGCT CTGATAGGAAAATGAG-3', reverse, 5'-GATACTCA GCAGCATCTCAGG-3'. PCR conditions were as follows: initial denaturation at $95^{\circ} \mathrm{C}$ for $5 \mathrm{~min}$, followed by 40 cycles of denaturation at $94^{\circ} \mathrm{C}$ for $20 \mathrm{~s}$, annealing at $56^{\circ} \mathrm{C}$ for $20 \mathrm{~s}$ and elongation at $72^{\circ} \mathrm{C}$ for $20 \mathrm{~s}$, and final extension at $72^{\circ} \mathrm{C}$ for $10 \mathrm{~min}$. We sequenced purified PCR products in an MJ Research PTC-225 Peltier Thermal Cycler using ABI PRISM ${ }^{\circledR}$ BigDye $^{\mathrm{TM}}$ Terminator Cycle Sequencing Kits and AmpliTaq ${ }^{\mathbb{B}}$ DNA polymerase (FS enzyme) (Applied Biosystems). Single-pass sequencing was performed on each template using the forward primer. The fluorescence-labeled fragments obtained were purified from unincorporated terminators by ethanol precipitation, resuspended in distilled water and subjected to electrophoresis in an ABI $3730 \times 1$ sequencer (Applied Biosystems).

\section{Statistical Analysis}

Statistical analysis was performed with SPSS software (version 11.0, SPSS Inc., Chicago, IL, USA). $\chi^{2}$ and Fisher's exact tests were used when comparing frequencies between groups. Factors independently associated with nodal metastasis were tested by stepwise logistic regression analysis. Probability values less than 0.05 were considered statistically significant.

\section{Results}

\section{Clinicopathological Features of Papillary Microcarcinomas with Lymph Node Metastasis}

To identify the clinicopathological variables associated with lymph node metastasis of papillary microcarcinoma, we compared the clinicopathological features of 74 patients with lymph node metastasis with those of 124 patients without lymph node metastasis. Papillary microcarcinomas with lymph node metastasis were characterized by large tumor size $(\geq 5 \mathrm{~mm} ; P<0.001)$, extrathyroidal extension $(P<0.001)$, multifocality $(P=0.002)$ and sclerosis $(P=0.002)$. No significant differences were found between the two groups in terms of other clinicopathological variables, including patient age, gender, histological subtype and encapsulation (Table 2).

\section{Correlation of Immunohistochemical Findings and the Presence of the BRAF ${ }^{\mathrm{V} 600 \mathrm{E}}$ Mutation with Lymph Node Metastasis}

S100A4 was expressed in 136 cases (69\%) (Figure 1). Expression of S100A4 in the invasive fronts could be evaluated in 120 of 136 S100A4-positive cases. Of these 120 cases, 29 (24\%) showed stronger 
Table 2 Clinicopathological variables, immunohistochemical findings and presence of BRAF ${ }^{\mathrm{v} 600 \mathrm{E}}$ mutation in papillary microcarcinomas of the thyroid in relation to lymph node metastasis

\begin{tabular}{|c|c|c|c|c|}
\hline Parameter & & $\begin{array}{l}\text { Papillary microcarcinoma without } \\
\text { lymph node metastasis }(\mathrm{n}=124)\end{array}$ & $\begin{array}{l}\text { Papillary microcarcinoma with } \\
\text { lymph node metastasis }(\mathrm{n}=74)\end{array}$ & $\mathrm{P}$-value \\
\hline \multirow[t]{2}{*}{ Age of the patient } & $<45$ years & $50(40 \%)$ & $32(43 \%)$ & 0.686 \\
\hline & $\geq 45$ years & $74(60 \%)$ & $42(57 \%)$ & \\
\hline \multirow[t]{2}{*}{ Size of tumor } & $<5 \mathrm{~mm}$ & $44(35 \%)$ & $2(3 \%)$ & $<0.001^{\mathrm{a}}$ \\
\hline & $\geq 5 \mathrm{~mm}$ & $80(65 \%)$ & $72(97 \%)$ & \\
\hline \multirow{2}{*}{ Extrathyroidal extension } & Ābsent & $94(76 \%)$ & $34(46 \%)$ & $<0.001^{\mathrm{a}}$ \\
\hline & Present & 30 (24\%) & $40(54 \%)$ & \\
\hline \multirow{2}{*}{ Multifocality } & Absent & $94(76 \%)$ & $40(54 \%)$ & $0.002^{\mathrm{a}}$ \\
\hline & Present & $30(24 \%)$ & $34(46 \%)$ & \\
\hline \multirow[t]{2}{*}{ Follicular variant } & No & $107(86 \%)$ & $69(93 \%)$ & 0.132 \\
\hline & Yes & $17(14 \%)$ & $5(7 \%)$ & \\
\hline \multirow[t]{2}{*}{ Sclerosis } & Absent & $60(48 \%)$ & $19(26 \%)$ & $0.002^{\mathrm{a}}$ \\
\hline & Present & $64(52 \%)$ & $55(74 \%)$ & \\
\hline \multirow[t]{2}{*}{ Encapsulation } & Absent & $96(77 \%)$ & $63(85 \%)$ & 0.187 \\
\hline & Present & $28(23 \%)$ & $11(15 \%)$ & \\
\hline \multirow{2}{*}{ S100A4 } & Negative & $50(40 \%)$ & $12(16 \%)$ & $<0.001^{\mathrm{a}}$ \\
\hline & Positive & $74(60 \%)$ & $62(84 \%)$ & \\
\hline \multirow[t]{2}{*}{ S100A4_inv $(n=120)^{\mathrm{b}}$} & Negative & $54(84 \%)$ & $37(66 \%)$ & $0.019^{\mathrm{a}}$ \\
\hline & Positive & $10(16 \%)$ & $19(34 \%)$ & \\
\hline \multirow[t]{2}{*}{ Cyclin D1 } & Negative & $58(47 \%)$ & $22(30 \%)$ & $0.018^{\mathrm{a}}$ \\
\hline & Positive & $66(53 \%)$ & $52(70 \%)$ & \\
\hline \multirow[t]{2}{*}{ P27 } & Negative & $80(65 \%)$ & $45(61 \%)$ & 0.601 \\
\hline & Positive & $44(35 \%)$ & $29(39 \%)$ & \\
\hline \multirow[t]{2}{*}{ MUC1 } & Negative & $67(54 \%)$ & $35(47 \%)$ & 0.359 \\
\hline & Positive & $57(46 \%)$ & $39(53 \%)$ & \\
\hline \multirow{2}{*}{$\begin{array}{l}B R A F^{\mathrm{V} 600 \mathrm{E}} \text { mutation } \\
(n=60)\end{array}$} & Negative & $16(53 \%)$ & $12(40 \%)$ & 0.301 \\
\hline & Positive & $14(47 \%)$ & $18(60 \%)$ & \\
\hline
\end{tabular}

${ }^{\mathrm{a}}$ Statistically significant.

${ }^{\mathrm{b}}$ S100A4_inv indicates strong expression of S100A4 in the invasive front. Statistical analysis was performed on 120 S100A4-positive cases.

expression of S100A4 in the invasive fronts than in the center of the tumor (Figure 1). There was intense nuclear staining for cyclin D1 in 118 cases (60\%). Loss of p27 expression was observed in 125 cases (63\%), and MUC1 expression was detected in 96 cases $(49 \%)$.

Of the immunohistochemical markers examined, S100A4 and cyclin D1 were significantly associated with lymph node metastasis $(P<0.001, P=0.018$, respectively; Table 2), and strong expression of S100A4 in the invasive fronts was more associated with lymph node metastasis, when analyzed in the 120 S100A4-positive cases $(P=0.019$; Table 2$)$.

Besides lymph node metastasis, S100A4 expression was correlated with sclerosis $(P=0.023)$. Cyclin D1 expression was significantly higher in the older age group ( $\geq 45$ year; 70 vs $45 \% ; P<0.001$ ) and large tumor $(\geq 5 \mathrm{~mm} ; 66$ vs $37 \% ; P<0.001)$, and lower in follicular variant (32 vs $63 \% ; P=0.005$ ). MUC1 expression was associated with large tumor size ( $\geq 5 \mathrm{~mm}$; 53 vs $35 \% ; P=0.034$ ). Loss of $\mathrm{p} 27$ was not correlated with any clinicopathological features including lymph node metastasis.

The $B R A F^{\mathrm{V} 600 \mathrm{E}}$ mutation was detected in 32 of the 60 cases $(53 \%)$ in which the analysis was possible. Its presence was not related to any clinicopathological features including lymph node metastasis (Table 2).

\section{Predictive Factors of Macrometastasis in Lymph Nodes}

Of the 74 patients with lymph node metastasis, 51 $(69 \%)$ showed macrometastasis and $23(31 \%)$ showed micrometastasis. As micrometastases are known to have no clinical relevance, ${ }^{22}$ we compared the clinicopathological features, immunohistochemical findings and the presence of the $B R A F^{\mathrm{V} 600 \mathrm{E}}$ mutation of 51 patients with macrometastasis with those of 147 patients without macrometastasis. Large tumor size ( $\geq 5 \mathrm{~mm} ; P<0.001)$, extrathyroidal extension $(P=0.001)$, multifocality $(P=0.001)$ and S100A4 expression $(P=0.005)$ were significantly associated with macrometastasis in lymph nodes (Table 3). And strong expression of S100A4 in the invasive fronts was also correlated with macrometastasis $(P=0.003)$ (Table 3$)$.

\section{Predictive Factors of Lateral Node Metastasis}

It has been reported that papillary microcarcinoma patients with clinically apparent lateral node metastasis are more likely to develop local recurrence in lymph nodes. ${ }^{23} \mathrm{We}$, therefore, analyzed the factors associated with lateral node metastasis detected by preoperative imaging study as well as histological examination. Tumor size $(P=0.044)$, multifocality 

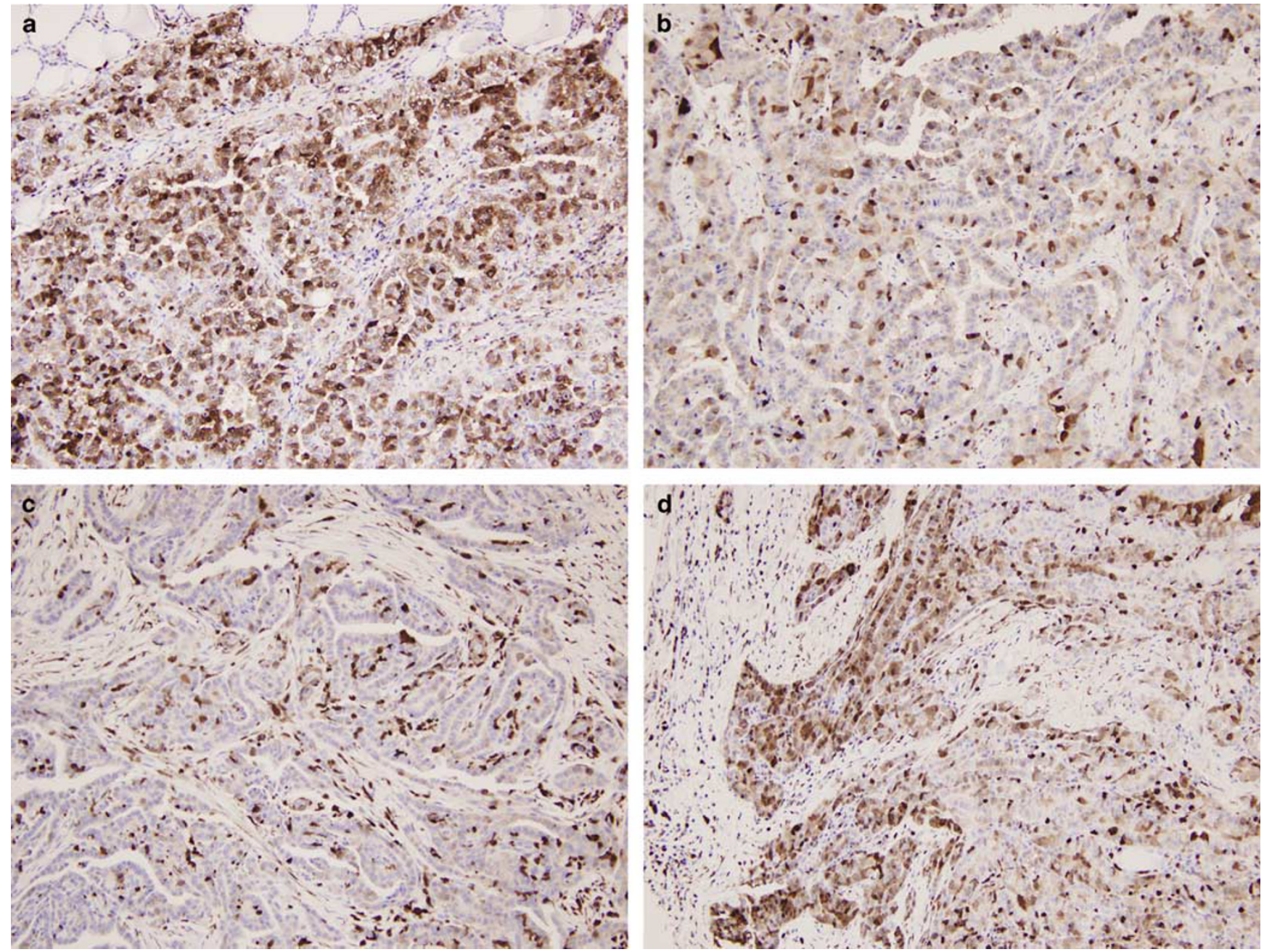

Figure 1 S100A4 expression in papillary microcarcinomas of the thyroid. (a) A case showing diffuse and strong expression of S100A4 in the cytoplasm and nuclei of tumor cells. (b) A case showing scattered cells positive for S100A4. (c) A case with no expression of S100A4. Tumor infiltrating lymphocytes, macrophages and blood vessels stain for S100A4. (d) A case showing stronger expression of S100A4 in the invasive fronts than in the center of the tumor.

Table 3 Predictive factors of macrometastasis in papillary microcarcinoma of the thyroid

\begin{tabular}{|c|c|c|c|c|}
\hline Parameter & & $\begin{array}{l}\text { Papillary microcarcinoma without } \\
\text { macrometastasis }(\mathrm{n}=147)\end{array}$ & $\begin{array}{l}\text { Papillary microcarcinoma with } \\
\text { macrometastasis }(\mathrm{n}=51)\end{array}$ & $\mathrm{P}$-value \\
\hline \multirow[t]{2}{*}{ Size of tumor } & $<5 \mathrm{~mm}$ & $44(30 \%)$ & $2(4 \%)$ & \multirow[t]{2}{*}{$<0.001^{\mathrm{a}}$} \\
\hline & $\geq 5 \mathrm{~mm}$ & $103(70 \%)$ & $49(96 \%)$ & \\
\hline \multirow{2}{*}{ Extrathyroidal extension } & Absent & $105(71 \%)$ & $23(45 \%)$ & \multirow{2}{*}{$0.001^{\mathrm{a}}$} \\
\hline & Present & $42(29 \%)$ & $28(55 \%)$ & \\
\hline \multirow{2}{*}{ Multifocality } & Absent & $109(74 \%)$ & $25(49 \%)$ & \multirow{2}{*}{$0.001^{\mathrm{a}}$} \\
\hline & Present & $38(26 \%)$ & $26(51 \%)$ & \\
\hline \multirow[t]{2}{*}{ S100A4 } & Negative & $54(37 \%)$ & $8(16 \%)$ & \multirow{2}{*}{$0.005^{\mathrm{a}}$} \\
\hline & Positive & $93(63 \%)$ & $43(84 \%)$ & \\
\hline \multirow[t]{2}{*}{ S100A4_inv $(n=120)^{\mathrm{b}}$} & Negative & $68(84 \%)$ & $23(59 \%)$ & \multirow[t]{2}{*}{$0.003^{\mathrm{a}}$} \\
\hline & Positive & $13(16 \%)$ & $16(41 \%)$ & \\
\hline
\end{tabular}

${ }^{\mathrm{a}}$ Statistically significant.

${ }^{\mathrm{b}}$ S100A4_inv indicates strong expression of S100A4 in the invasive front. Statistical analysis was performed on 120 S100A4-positive cases.

$(P=0.012)$ and S100A4 expression $(P=0.020)$ were significantly associated with lateral node metastasis (Table 4). And strong expression of S100A4 in invasive fronts was more strongly associated with lateral node metastasis, when analyzed in the 120 S100A4-positive cases $(P=0.006$; Table 4$)$. 
Table 4 Predictive factors of lateral node metastasis in papillary microcarcinoma of the thyroid

\begin{tabular}{|c|c|c|c|c|}
\hline Parameter & & $\begin{array}{l}\text { Papillary microcarcinoma without } \\
\text { lateral node metastasis }(\mathrm{n}=172)\end{array}$ & $\begin{array}{l}\text { Papillary microcarcinoma with } \\
\text { lateral node metastasis }(\mathrm{n}=26)\end{array}$ & $\mathrm{P}$-value \\
\hline \multirow[t]{2}{*}{ Size of tumor } & $<5 \mathrm{~mm}$ & $44(26 \%)$ & $2(8 \%)$ & \multirow[t]{2}{*}{$0.044^{\mathrm{a}}$} \\
\hline & $\geq 5 \mathrm{~mm}$ & $128(74 \%)$ & $24(92 \%)$ & \\
\hline \multirow{2}{*}{ Extrathyroidal extension } & $\overline{\text { Absent }}$ & $115(67 \%)$ & $13(50 \%)$ & \multirow{2}{*}{0.094} \\
\hline & Present & $57(33 \%)$ & $13(50 \%)$ & \\
\hline \multirow[t]{2}{*}{ Multifocality } & Absent & $122(71 \%)$ & $12(46 \%)$ & \multirow[t]{2}{*}{$0.012^{\mathrm{a}}$} \\
\hline & Present & $50(29 \%)$ & $14(54 \%)$ & \\
\hline \multirow[t]{2}{*}{ S100A4 } & Negative & $59(34 \%)$ & $3(12 \%)$ & \multirow[t]{2}{*}{$0.020^{\mathrm{a}}$} \\
\hline & Positive & $113(66 \%)$ & $23(88 \%)$ & \\
\hline \multirow{2}{*}{ S100A4_inv $(n=120)^{\mathrm{b}}$} & Negative & $80(81 \%)$ & $11(52 \%)$ & \multirow[t]{2}{*}{$0.006^{\mathrm{a}}$} \\
\hline & Positive & $19(19 \%)$ & $10(48 \%)$ & \\
\hline
\end{tabular}

${ }^{\mathrm{a}}$ Statistically significant.

${ }^{\mathrm{b}}$ S100A4_inv indicates strong expression of S100A4 in the invasive front. Statistical analysis was performed on 120 S100A4-positive cases.

\section{Multivariate Analysis}

Multivariate analysis revealed that the factors independently associated with lymph node metastasis were tumor size of $5 \mathrm{~mm}$ or more (odds ratio 14.882; 95\% confidence interval (CI), 3.280-67.529; $P<0.001$ ), extrathyroidal extension (odds ratio 2.169; 95\% CI, 1.052-4.473; $P=0.036$ ), multifocality (odds ratio 2.927; 95\% CI, 1.412-6.065; $P=0.004$ ) and S100A4 expression (odds ratio 3.137; 95\% CI, 1.399-7.032; $P=0.006)$; sclerosis and cyclin D1 expression were not independently associated with lymph node metastasis. Tumor size of $5 \mathrm{~mm}$ or more (odds ratio 8.211; 95\% CI, 1.821-37.017; $P=0.006$ ), multifocality (odds ratio $2.963 ; 95 \% \mathrm{CI}$, 1.442-6.088; $P=0.003$ ) and S100A4 expression (odds ratio $2.789 ; 95 \% \mathrm{CI}, 1.162-6.698 ; P=0.02$ ) were also revealed to be independent predictive factors of macrometastasis in lymph nodes. In terms of lateral node metastasis, multifocality (odds ratio 2.731; 95\% CI, 1.155-6.457; $P=0.022$ ) and S100A4 expression (odds ratio 3.574; 95\% CI, 1.012-12.620; $P=0.048$ ) were proved to be independent predictive factors.

\section{Discussion}

In the present study, we defined the predictive factors of lymph node metastasis in a large series of papillary microcarcinomas by analyzing clinicopathological variables including tumor size, extrathyroidal extension and multifocality, expression of S100A4, cyclin D1, p27 and MUC1, and the presence of the $B R A F^{v 600 E}$ mutation. We found that tumor size of $5 \mathrm{~mm}$ or more, extrathyroidal extension, multifocality, sclerosis, and the expression of S100A4 and cyclin D1 predicted lymph node metastasis. Moreover, tumor size of $5 \mathrm{~mm}$ or more, multifocality and expression of S100A4, especially its strong expression in the invasive fronts, were found to be associated with macrometastasis and lateral node metastasis. On multivariate analysis, multifocality and expression of S100A4 were proved to be common independent predictive factors of lymph node metastasis, macrometastasis and lateral node metastasis.

As mentioned earlier, most papillary microcarcinomas follow an indolent clinical course. ${ }^{5,6}$ However, there have been an increasing number of reports of aggressive papillary microcarcinomas. Papillary microcarcinomas may present with up to $35 \%$ multifocality, ${ }^{24}$ up to $30 \%$ lymph node metastasis, ${ }^{3}$ up to $28 \%$ extrathyroidal extension ${ }^{3}$ and up to $2 \%$ distant metastases. ${ }^{2}$ In our study, some features were even more prevalent: multifocality was found in $32 \%$ of the papillary microcarcinomas, extrathyroidal extension in $35 \%$ and regional lymph node metastasis in $37 \%$, although direct comparison would be inappropriate, because a large number of our cases were non-incidental papillary microcarcinoma with lymph node dissection. Moreover, some authors have insisted that there was no statistically significant difference between papillary microcarcinomas and papillary thyroid carcinomas at clinical follow-up. ${ }^{11,24}$ Thus, establishing the predictive factors that differentiate between silent and potentially aggressive papillary microcarcinomas would be of great value.

S100A4 is a member of the S100 family of calcium-binding proteins, also known as metastasin, fibroblast-specific protein, pEL-98, 18A2, CAPL or calvasculin. ${ }^{25}$ Many in vitro and in vivo studies in rodents have provided evidence that S100A4 is directly involved in tumor progression and metastasis. ${ }^{25,26}$ Hence, the prognostic significance of S100A4 expression has been evaluated in various human cancers, and it has been shown to be a prognostic marker in breast, pancreatic, prostate, gallbladder, esophageal, gastric and non-small cell lung cancers. ${ }^{27}$ With regard to thyroid cancer, S100A4 was reported to be the most highly expressed gene in a thyroid carcinoma cell line with high metastatic potential, and its overexpression was observed in most advanced thyroid carcinomas including papillary thyroid carcinomas and anaplastic carcinomas. ${ }^{28}$ S100A4 expression was also elevated in the 
lymph node metastases of papillary thyroid carcinomas compared with primary tumors, and in the tumor-invading front compared to the central region, suggesting that S100A4 overexpression is associated with invasion and metastasis of the papillary thyroid carcinomas. ${ }^{14}$ In our study, S100A4 was strongly associated with lymph node metastasis and was found to be an independent predictive factor of lymph node metastasis in papillary microcarcinomas, suggesting that it is also associated with metastasis of papillary microcarcinomas. Moreover, its significant association with macrometastasis and lateral node metastasis confirmed that it could be a predictive factor for metastasis in lymph node and poor prognosis. Furthermore, cases with strong expression of S100A4 in invasive fronts showed a stronger association with lymph node metastasis, macrometastasis and lateral node metastasis, suggesting that S100A4 overexpression is involved in the invasion, and thus the metastasis of papillary microcarcinomas.

Although S100A4 was strongly associated with nodal metastasis of papillary microcarcinomas, its expression was not correlated with tumor size (61\% in $<5 \mathrm{~mm}$ vs $71 \%$ in $\geq 5 \mathrm{~mm} ; P=0.192$ ). Thus, S100A4 expression may be associated with early metastatic potential of papillary microcarcinoma that is not necessarily correlated with tumor size. Recently, CEACAM1 expression was also reported to be associated with metastatic spread, but not with tumor growth of thyroid cancer. ${ }^{29}$

In our study, S100A4 was expressed in $69 \%$ of papillary microcarcinomas, which is lower than in a previous study of large papillary thyroid carcinomas. ${ }^{14}$ Ito et $a l^{30}$ also investigated the expression of S100A4 in papillary thyroid carcinomas including 58 microcarcinomas and found that S100A4 was positive in all cases. The difference in frequency of expression may be due to the differences between the cutoff points used to define positive staining and different pools of cases; we regarded cases as positive for S100A4 when more than $10 \%$ of the tumor cells were stained, whereas Zou et $a l^{14}$ and Ito et $a l^{30}$ considered cases positive when any tumor cell was found to express S100A4. Also, in our study, only $37 \%$ of the papillary microcarcinomas had lymph node metastasis, whereas Zou et $a l^{14}$ examined 28 papillary thyroid carcinomas all of which had regional lymph node or distant metastases, and in the study by Ito et al, ${ }^{30} 70 \%$ of the 115 papillary thyroid carcinomas had lymph node metastasis. Therefore, the higher rate of S100A4 expression in their studies may reflect the greater metastatic potential of their cases.

Cyclin D1 overexpression and p27 underexpression have been reported to be predictive factors for lymph node metastasis in papillary microcarcinomas. ${ }^{19-21}$ Our data showed that cyclin D1 expression is associated with lymph node metastasis, but not with macrometastasis or lateral node metastasis. And it failed to be independent predictive factor for lymph node metastasis, probably because of its strong association with tumor size $(P<0.001)$. P27 did not show any association with lymph node metastasis. This disparity may result from the difference in scale of the studies and different criteria for lymph node metastases: we examined 198 papillary microcarcinomas as compared with 56 and 55, respectively, of Khoo et $a l^{20}$ and Ito et $a l^{21}$. Again, we identified cases with lymph node metastasis through histological examination, and therefore, included microscopic metastases also, whereas the other studies only included cases with gross or clinically apparent metastases.

There have been conflicting data on the clinical significance of the $B R A F^{\mathrm{V} 600 \mathrm{E}}$ mutation: several studies have reported that this mutation is related to poor prognostic factors in papillary thyroid carcinoma, ${ }^{17,31,32}$ whereas others have found no association between them,,$^{33-35}$ as in our study.

As expected, we found that tumor size of $5 \mathrm{~mm}$ or more, extrathyroidal spread and multifocality were associated with lymph node metastasis or macrometastasis at presentation. Although tumor size is measurable preoperatively, extrathyroidal extension (especially microscopic) and multifocality cannot be identified prior to histopathological examination. Thus, preoperative evaluation of tumor size and the expression of S100A4 in cytological specimens of papillary microcarcinomas should be helpful in guiding therapy for patients with papillary microcarcinoma.

In conclusion, S100A4 immunohistochemistry appears to be valuable for predicting metastatic potential in papillary microcarcinoma, and positive S100A4 immunostaining, especially in the invasive fronts of the primary tumor, seems to indicate the presence of lymph node metastasis. Although its clinical significance needs to be further evaluated, S100A4 expression may discriminate between 'more aggressive forms' and clinically silent papillary microcarcinomas.

\section{Acknowledgement}

This study was supported by Seoul National University Bundang Hospital, Seongnam, Korea (Research Fund Grant No. 02-2006-028).

\section{References}

1 LiVolsi VA, Albores-Saavedra J, Asa SL, et al. Papillary carcinoma In: DeLellis RA, Lloyd RV, Heitz PU, Eng C (eds). World Health Organization Classification of Tumors: Pathology and Genetics of Tumors of Endocrine Organs. IARC Press: Lyon, 2004, pp 57-66.

2 Roti E, Rossi R, Trasforini G, et al. Clinical and histological characteristics of papillary thyroid microcarcinoma: results of a retrospective study in 243 patients. J Clin Endocrinol Metab 2006;91:2171-2178.

3 Lee J, Rhee Y, Lee S, et al. Frequent, aggressive behaviors of thyroid microcarcinomas in korean patients. Endocr J 2006;53:627-632. 
4 Cheema Y, Olson S, Elson D, et al. What is the biology and optimal treatment for papillary microcarcinoma of the thyroid? J Surg Res 2006;134:160-162.

5 Hay ID, Grant CS, van Heerden JA, et al. Papillary thyroid microcarcinoma: a study of 535 cases observed in a 50-year period. Surgery 1992;112:1139-1146.

6 Baudin E, Travagli JP, Ropers J, et al. Microcarcinoma of the thyroid gland: the Gustave-Roussy Institute experience. Cancer 1998;83:553-559.

7 Yamashita H, Noguchi S, Murakami N, et al. Extracapsular invasion of lymph node metastasis. A good indicator of disease recurrence and poor prognosis in patients with thyroid microcarcinoma. Cancer 1999;86: 842-849.

8 Schlumberger MJ. Papillary and follicular thyroid carcinoma. N Engl J Med 1998;338:297-306.

9 Sugitani I, Fujimoto Y. Symptomatic vs asymptomatic papillary thyroid microcarcinoma: a retrospective analysis of surgical outcome and prognostic factors. Endocr J 1999;46:209-216.

10 Chow SM, Law SC, Chan JK, et al. Papillary microcarcinoma of the thyroid-Prognostic significance of lymph node metastasis and multifocality. Cancer 2003; 98:31-40.

11 Pellegriti G, Scollo C, Lumera G, et al. Clinical behavior and outcome of papillary thyroid cancers smaller than $1.5 \mathrm{~cm}$ in diameter: study of 299 cases. J Clin Endocrinol Metab 2004;89:3713-3720.

12 Greene FL, Page DL, Fleming ID, et al. (eds). AJCC Cancer Staging Manual, 6th edn. Springer: New York, 2002.

13 Khoo ML, Beasley NJ, Ezzat S, et al. Overexpression of cyclin D1 and underexpression of p27 predict lymph node metastases in papillary thyroid carcinoma. J Clin Endocrinol Metab 2002;87:1814-1818.

14 Zou M, Al-Baradie RS, Al-Hindi H, et al. S100A4 (Mts1) gene overexpression is associated with invasion and metastasis of papillary thyroid carcinoma. Br J Cancer 2005;93:1277-1284.

15 Wreesmann VB, Sieczka EM, Socci ND, et al. Genomewide profiling of papillary thyroid cancer identifies MUC1 as an independent prognostic marker. Cancer Res 2004;64:3780-3789.

16 Karlidag T, Cobanoglu B, Keles E, et al. Expression of Bax, p53, and p27/kip in patients with papillary thyroid carcinoma with or without cervical nodal metastasis. Am J Otolaryngol 2007;28:31-36.

17 Xing M, Westra WH, Tufano RP, et al. BRAF mutation predicts a poorer clinical prognosis for papillary thyroid cancer. J Clin Endocrinol Metab 2005;90: 6373-6379.

18 Trovisco V, Soares P, Sobrinho-Simoes M. B-RAF mutations in the etiopathogenesis, diagnosis, and prognosis of thyroid carcinomas. Hum Pathol 2006;37: 781-786.

19 Khoo ML, Freeman JL, Witterick IJ, et al. Underexpression of p27/Kip in thyroid papillary microcarcinomas with gross metastatic disease. Arch Otolaryngol Head Neck Surg 2002;128:253-257.

20 Khoo ML, Ezzat S, Freeman JL, et al. Cyclin D1 protein expression predicts metastatic behavior in thyroid papillary microcarcinomas but is not associated with gene amplification. J Clin Endocrinol Metab 2002;87: 1810-1813.

21 Ito Y, Uruno T, Takamura Y, et al. Papillary microcarcinomas of the thyroid with preoperatively detectable lymph node metastasis show significantly higher aggressive characteristics on immunohistochemical examination. Oncology 2005;68:87-96.

22 Gemsenjäger E, Perren A, Seifert B, et al. Lymph node surgery in papillary thyroid carcinoma. J Am Coll Surg 2003;197:182-190.

23 Ito Y, Tomoda C, Uruno T, et al. Preoperative ultrasonographic examination for lymph node metastasis: usefulness when designing lymph node dissection for papillary microcarcinoma of the thyroid. World J Surg 2004;28:498-501.

24 Cappelli C, Castellano M, Braga M, et al. Aggressiveness and outcome of papillary thyroid carcinoma (PTC) vs microcarcinoma (PMC): a mono-institutional experience. J Surg Oncol 2007;95:555-560.

25 Garrett SC, Varney KM, Weber DJ, et al. S100A4, a mediator of metastasis. J Biol Chem 2006;281:677-680

26 Helfman DM, Kim EJ, Lukanidin E, et al. The metastasis associated protein S100A4: role in tumour progression and metastasis. Br J Cancer 2005;92: 1955-1958.

27 Mazzucchelli L. Protein S100A4: too long overlooked by pathologists? Am J Pathol 2002;160:7-13.

28 Zou M, Famulski KS, Parhar RS, et al. Microarray analysis of metastasis-associated gene expression profiling in a murine model of thyroid carcinoma pulmonary metastasis: identification of S100A4 (Mts1) gene overexpression as a poor prognostic marker for thyroid carcinoma. J Clin Endocrinol Metab 2004;89: 6146-6154.

29 Liu W, Wei W, Winer D, et al. CEACAM1 impedes thyroid cancer growth but promotes invasiveness: a putative mechanism for early metastases. Oncogene 2007;26:2747-2758.

30 Ito Y, Yoshida H, Tomoda C, et al. S100A4 expression is an early event of papillary carcinoma of the thyroid. Oncology 2004;67:397-402.

31 Namba $H$, Nakashima M, Hayashi $T$, et al. Clinical implication of hot spot BRAF mutation, V599E, in papillary thyroid cancers. J Clin Endocrinol Metab 2003;88:4393-4397.

32 Nikiforova MN, Kimura ET, Gandhi M, et al. BRAF mutations in thyroid tumors are restricted to papillary carcinomas and anaplastic or poorly differentiated carcinomas arising from papillary carcinomas. J Clin Endocrinol Metab 2003;88:5399-5404.

33 Fugazzola L, Mannavola D, Cirello V, et al. BRAF mutations in an Italian cohort of thyroid cancers. Clin Endocrinol (Oxf) 2004;61:239-243.

$34 \mathrm{Kim}$ TY, Kim WB, Song JY, et al. The BRAF mutation is not associated with poor prognostic factors in Korean patients with conventional papillary thyroid microcarcinoma. Clin Endocrinol (Oxf) 2005;63:588-593.

35 Wojciechowska K, Lewinski A. BRAF mutations in papillary thyroid carcinoma. Endocr Regul 2006;40: 129-138. 